\title{
Carbonization of Coal Pitch with Additives
}

\author{
O. F. Sidorov \\ Yeltsin Ural Federal University, Yekaterinburg, Russia \\ e-mail: sidorole@mail.ru \\ OAO Vostochnaya Nauchno-Issledovatel'skii Uglekhimicheskii Institut, Yekaterinburg, Russia
}

Received November 15, 2012

\begin{abstract}
The ability of organic and inorganic additives (polyethylene terephthalate, titanium dioxide, finely disperse carbon, petroleum bitumen) to reduce the carcinogenic impact of coal-pitch carbonization is studied. Additives may reduce the quantity of pitch sublimates and their content of carcinogenic polycyclic aromatic hydrocarbons. Some additives are able to reduce the benz $[a]$ pyrene content in the exhaust gases, but its complete elimination is impossible, since benz $[a]$ pyrene is a natural product of the high-temperature pyrolysis of organic materials. For this reason, additions of petroleum products to coal pitch cannot reduce the benz $[a]$ pyrene emissions in the exhaust gases.
\end{abstract}

DOI: $10.3103 / \mathrm{S} 1068364 X 13010067$

At coke plants, there are numerous organic and inorganic additives to coal pitch. Most are condensing additives, which accelerate the polymerization and condensation so as to increase the yield of coke residue. Others include plasticizing additives, which improve the rheological, wetting, and steeping properties of binder pitch; and structuring additives, which determine the microstructure, porosity, and electrophysical and physicomechanical properties of pitch carbonizates.

In the present work, we investigate the influence of additives on the gas-liberation dynamics and on the content of benz[a]pyrene and other carcinogenic polycyclic aromatic hydrocarbons in the products of pitch carbonization - pitch sublimates and the exhaust gases after condensation. The most important consideration is the content of toxic polycyclic aromatic hydrocarbons in the exhaust gases. These are often the primary emissions from pitch processing and must be regarded as a hazardous atmospheric pollutant. Thus, in our experiments, we measure the benz $[a]$ pyrene content in the exhaust gases from the laboratory coking of high-temperature pitch, by the method in [1].

The additives are introduced in two ways:

(1) mixing with the industrial pitch sample immediately before carbonization;

(2) preliminary heating of a mixture of pitch with the additive, so as to obtain modified pitch.

Table 1 presents the types of pitch employed. Table 2 summarizes the basic experimental results.

The influence of VOKS condensing additive was investigated in [1]. This additive is able to reduce the carcinogenic impact by at least three quarters. Gasliquid chromatography shows that this is due to selec- tive reaction of the thermal-destruction products of the VOKS additive with the most high-molecular carcinogenic polycyclic aromatic hydrocarbons, with considerable decrease in the yield of pitch sublimates and reduction in their content of carcinogenic polycyclic aromatic hydrocarbons. Thus, the benz $[a]$ pyrene content in pitch sublimates from the carbonization of pitch modified by VOKS is reduced by $37 \%$, the content of inden[1,2,3-c, $d]$ pyrene by $53 \%$, the content of dibenzo[ $a, h]$ anthracene by $42 \%$, and the content of higher-molecular benz $[g, h, i]$ perylene by $69 \%$.

In the carbonization of pitch with the addition of VOKS immediately before carbonization, the gas-liberation peak is shifted to higher temperatures. By contrast, if the high-temperature pitch is modified with VOKS, the position of the gas-liberation peak is unchanged.

Polyethylene phthalate (PET) is an effective additive, as shown by an analysis of our research and literature data [2-5]. PET is a chemically active reagent that affects the gas-liberation dynamics in the carbon-

Table 1. Pitch samples

\begin{tabular}{l|c|c|c|l}
\hline \multirow{2}{*}{ Sample } & \multicolumn{3}{|c|}{ Characteristics } & Pitch prep- \\
& $T_{\mathrm{p}},{ }^{\circ} \mathrm{C}$ & $\alpha, \%$ & $\mathrm{BP} * \%$ & aration \\
\hline $\begin{array}{l}\text { High-temperature } \\
\text { pitch A (HTP A) }\end{array}$ & 152 & 52 & 0.95 & $\begin{array}{l}\text { Industrial } \\
\text { sample }\end{array}$ \\
$\begin{array}{l}\text { High-temperature } \\
\text { pitch B (HTP B) }\end{array}$ & 145 & 51.8 & 1.3 & $\begin{array}{l}\text { Industrial } \\
\text { sample }\end{array}$ \\
$\begin{array}{l}\text { Medium-tempera- } \\
\text { ture pitch (MTP) }\end{array}$ & 77 & 7.6 & - & $\begin{array}{l}\text { Industrial } \\
\text { sample }\end{array}$ \\
\hline
\end{tabular}

* By BP, we denote the benz $[a]$ pyrene content. 
Table 2. Experimental results

\begin{tabular}{|c|c|c|c|c|c|c|c|c|c|c|}
\hline \multirow{2}{*}{$\begin{array}{c}\text { Experi- } \\
\text { ment }\end{array}$} & \multirow{2}{*}{$\begin{array}{l}\text { Carbonized } \\
\text { sample }\end{array}$} & \multirow{2}{*}{$\begin{array}{l}\text { Addi- } \\
\text { tive, } \%\end{array}$} & \multicolumn{3}{|c|}{ Yield of carbonization products } & \multicolumn{3}{|c|}{$\mathrm{BP}, \mathrm{ng} / \mathrm{g}$ of pitch } & \multirow{2}{*}{$T_{\mathrm{gl}},{ }^{\circ} \mathrm{C}$} & \multirow{2}{*}{$\begin{array}{c}\text { Total BP } \\
\mu \mathrm{g} / \mathrm{m}^{3}\end{array}$} \\
\hline & & & coke, $\%$ & $\operatorname{tar}, \%$ & $\begin{array}{l}\text { gas, } \mathrm{mg} / \mathrm{g} \text { of } \\
\text { pitch }\end{array}$ & $\begin{array}{l}\text { up to } \\
750^{\circ} \mathrm{C}\end{array}$ & $\begin{array}{l}750- \\
800^{\circ} \mathrm{C}\end{array}$ & $\begin{array}{l}\text { beyond } \\
800^{\circ} \mathrm{C}\end{array}$ & & \\
\hline 1 & HTP A & 0 & 78.0 & 17.2 & 236 & 22.9 & 17.6 & 11.0 & 535 & 304.1 \\
\hline 2 & НТР В & 0 & 78.2 & 15.8 & 252 & 33.4 & 11.3 & - & 548 & 355.4 \\
\hline 3 & HTP A + VOKS & 12.0 & 86.4 & 5.3 & 218 & 49.1 & 12.3 & - & 550 & 281.5 \\
\hline 4 & HTP B + PET & 1.7 & 83.9 & 11.1 & 274 & 159 & 282 & - & 549 & 626.9 \\
\hline 5 & $\mathrm{HTP} \mathrm{B}+\mathrm{TiO}_{2}$ & 3.8 & 72.7 & 21.9 & 183 & \multicolumn{2}{|c|}{27.3} & - & 447 & 219.8 \\
\hline 6 & HTP B $\left(\mathrm{TiO}_{2}\right)$ & 1.4 & 83.2 & 11.8 & 202 & \multicolumn{2}{|c|}{37.7} & - & 492 & 265.9 \\
\hline 7 & HTP A (FDC) & 9.0 & 80.6 & 13.4 & 264 & 29.1 & 7.1 & 9.6 & 549 & 138.3 \\
\hline 8 & HTP A + FDC & 7.4 & 80.0 & 15.1 & 212 & \multicolumn{2}{|c|}{23.0} & - & 550 & 99.0 \\
\hline 9 & $\mathrm{MTP}+\mathrm{FDC}$ & 5.0 & 78.0 & 16.2 & 358 & 39.8 & 14.0 & 7.1 & 545 & 436.5 \\
\hline 10 & MTP & 0 & 73.2 & 22.8 & 164 & \multicolumn{2}{|c|}{27.9} & - & 620 & 170.4 \\
\hline 11 & HTP A + bitumen & 13.5 & 79.0 & 27.5 & 476 & 50.5 & \multicolumn{2}{|c|}{31.5} & 545 & 172.2 \\
\hline 12 & HTP A & 0 & 65.8 & 29.2 & 224 & \multicolumn{2}{|c|}{164.4} & - & - & 734.1 \\
\hline 13 & HTP A (FDC) & 9.0 & 70.0 & 25.0 & 224 & \multicolumn{2}{|c|}{109.7} & - & - & 489.8 \\
\hline
\end{tabular}

Note: We employ the following notation: BP, benz $[a]$ pyrene content in the gas; $T_{\mathrm{gl}}$-temperature of maximum gas liberation; FDC, finely disperse carbon.

ization of high-temperature pitch and hence the composition of the atmospheric emissions, including carcinogenic emissions. We may characterize PET as a thermoplastic polymer of diglycol terephthalate (molecular mass 20000-40000), with a softening temperature of $\sim 245^{\circ} \mathrm{C}$, a melting point of $\sim 260^{\circ} \mathrm{C}$ and an initial decomposition temperature of around $300^{\circ} \mathrm{C}$. We know that PET affects the chemical processes in the low-temperature stage during the carbonization of pitch-coke composites and facilitates the formation of pitch semicoke at $440^{\circ} \mathrm{C}$ (as against 540$550^{\circ} \mathrm{C}$ in the absence of additive) [2]. We also know that PET facilitates the formation of carbonizate with isotropic texture [3, 4]; and reduces the fluidity of the coal's organic mass in the thermoplastic state [5].

The PET samples considered are small pieces (10$15 \mathrm{~g})$ cut from plastic domestic bottles, which are placed in a tubular quartz reactor (diameter $30 \mathrm{~mm}$ ) and coked by the method described for high-temperature pitch in [1].

The pyrolysis of PET may be expressed in the form

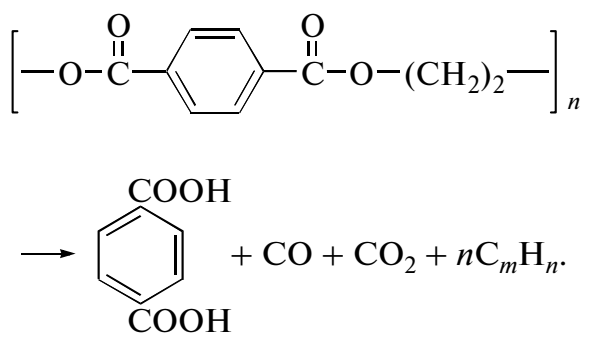

In the carbonization of high-temperature pitch, we obtain the following products: terephthalic acid in the form of yellow crystals subliming in the upper part of the reactor and condensate receiver $(\sim 17-20 \%)$; coke-like residue $(\sim 20-22 \%)$; and gaseous products in the form of carbon oxides and saturated hydrocarbons $(55-60 \%)$.

In subsequent experiments on the same apparatus, we investigate the influence of PET on the gas-liberation dynamics of high-temperature pitch. To simulate industrial conditions, we use a low pressure (30$50 \mathrm{~mm} \mathrm{H}_{2} \mathrm{O}$ ) in the coking of high-temperature pitch with and without the additive. According to thermogravimetric data, the PET begins to break down at $\sim 300^{\circ} \mathrm{C}$, with maximum gas liberation at $410^{\circ} \mathrm{C}$; solid coke residue is formed at $440-450^{\circ} \mathrm{C}$. Up to $550^{\circ} \mathrm{C}$, the coke residue remains unchanged. It begins to lose mass again at $650^{\circ} \mathrm{C}$ (obviously by dehydrogenation and decarboxylation). Above $750^{\circ} \mathrm{C}$, a coal-like product is formed, with $99.1 \%$ carbon, $0.1-0.3 \%$ hydrogen, and $0.5-0.6 \%$ oxygen.

In chemical terms, the PET provides carboxyl groups in terephthalic acid, which react with the evaporating pitch components to form carbonyl groups. That is confirmed by the IR spectra of pitch samples heated with PET to $300-400^{\circ} \mathrm{C}$ : the absorption band at $1710-1720 \mathrm{~cm}^{-1}$ is increased on account of vibration of the carbonyl groups [3]. As a result, the hydrocarbons that would otherwise leave the pitch are retained when PET is present.

For the same reasons, in our experiments on the carbonization of high-temperature pitch with PET, the gas liberation declines at $400-500^{\circ} \mathrm{C}$, while the yield of coke residue is increased. The increased gas 
liberation at $700-800^{\circ} \mathrm{C}$ in the carbonization of hightemperature pitch with PET indicates greater dehydrogenation, as confirmed by the more pronounced shrinkage of the coke beads and their elevated carbon content.

As in the case of VOKS additive, experiments on the carbonization of high-temperature pitch with PET show a pronounced condensing effect, to judge from the increased yield of coke residue $(83.9 \%)$. The reduced yield of pitch tar indicates a smaller yield of carcinogenic polycyclic aromatic hydrocarbons. However, on account of the greater gas liberation (Fig. 1), the total benz[a]pyrene content in the exhaust gases is at record levels (Table 2, experiment 4).

Thus, adding PET to high-temperature pitch does not reduce the benz $[a]$ pyrene content in the exhaust gases and therefore is not an effective approach.

Some metals or their oxides have a catalytic effect on the thermolysis of coal pitch. Heat treatment of coal pitch in the range $300-410^{\circ} \mathrm{C}$ shows that adding $0.5 \% \mathrm{TiO}_{2}$ markedly reduces the content of carcinogenic polycyclic aromatic hydrocarbons in the pitch and the pitch sublimates [6].

Thus, we find that adding titanium dioxide impairs the quality of high-temperature pitch, by reducing the softening temperature, the content of components insoluble in toluene and quinoline, the content of $\beta$ tar, and the yield of coke residue over practically the whole temperature range. On that basis, titanium

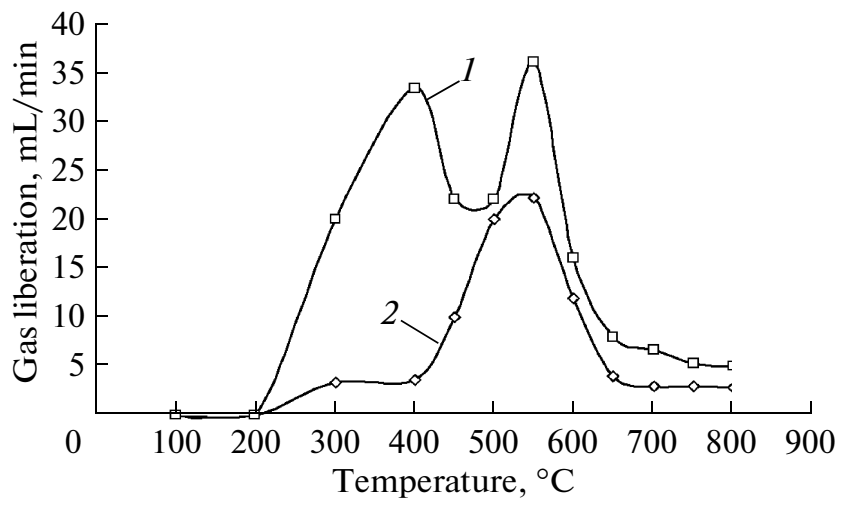

Fig. 1. Carbonization of pitch with PET: (1) HTP B + $1.5 \%$ PET; (2) HTP B.

dioxide may be regarded as a condensation inhibitor, in contrast to condensing additives.

On heating pitch with titanium dioxide, the content of practically all of the chromatographically determined carcinogenic polycyclic aromatic hydrocarbons is significantly reduced, as follows from the data in [6] (summarized in Table 3). The reduction is greatest at $300^{\circ} \mathrm{C}$. The reduction in the carcinogenic impact by adding $\mathrm{TiO}_{2}$ is confirmed by the minimal content of carcinogenic polycyclic aromatic hydrocarbons in the pitch sublimates.

Table 3. Influence of added $\mathrm{TiO}_{2}$ on the composition of carcinogenic polycyclic aromatic hydrocarbons in the pitch

\begin{tabular}{|c|c|c|c|c|c|}
\hline \multirow{3}{*}{ No. } & \multirow{3}{*}{ Hydrocarbon } & \multicolumn{4}{|c|}{ Concentration of polycyclic aromatic hydrocarbon in pitch, $\%$} \\
\hline & & \multicolumn{2}{|c|}{ at $300^{\circ} \mathrm{C}$} & \multicolumn{2}{|c|}{ at $380^{\circ} \mathrm{C}$} \\
\hline & & without additive & with additive & without additive & with additive \\
\hline 1 & Naphthalene & $0.01-0.06$ & $0.01-0.06$ & $0.01-0.06$ & $0.01-0.06$ \\
\hline 1 & Acenaphthylene & $0.01-0.06$ & $0.01-0.06$ & $0.01-0.06$ & $0.01-0.06$ \\
\hline 3 & Acenaphthene & $0.01-0.06$ & $0.01-0.06$ & $0.01-0.06$ & $0.01-0.06$ \\
\hline 4 & Fluorene & $0.01-0.06$ & $0.01-0.06$ & $0.01-0.06$ & $0.01-0.06$ \\
\hline 5 & Phenanthrene & 0.3 & 0.1 & 0.3 & 0.15 \\
\hline 6 & Anthracene & 0.08 & 0.05 & 0.9 & 0.03 \\
\hline 7 & Fluoranthene & 1.2 & 0.5 & 1.35 & 0.92 \\
\hline 8 & Pyrene & 1.4 & 0.58 & 1.5 & 0.5 \\
\hline 9 & Benz $[a]$ anthracene & 0.92 & 0.4 & 1.09 & 0.95 \\
\hline 10 & Chrysene & 1.05 & 0.1 & 1.1 & 0.23 \\
\hline 11 & Benz $[b+k]$ fluoranthene & 2.0 & 1.0 & 2.4 & 0.6 \\
\hline 12 & Benz $[e]$ pyrene & 0.8 & 0.2 & 0.9 & 0.3 \\
\hline 13 & Benz $[a] p y r e n e$ & 1.06 & 0.23 & 1.25 & 0.32 \\
\hline 14 & Perylene & 0.6 & 0.08 & 0.24 & 0.2 \\
\hline 15 & Inden $[1,2,3-c, d]$ pyrene + dibenzo $[a, h]$ anthracene & 1.0 & 0.3 & 1.5 & 0.4 \\
\hline 16 & Benz $[g, h, i]$ perylene & 0.7 & 0.2 & 0.8 & 0.25 \\
\hline
\end{tabular}

Note: Carcinogenic polycyclic aromatic hydrocarbons are in bold. 


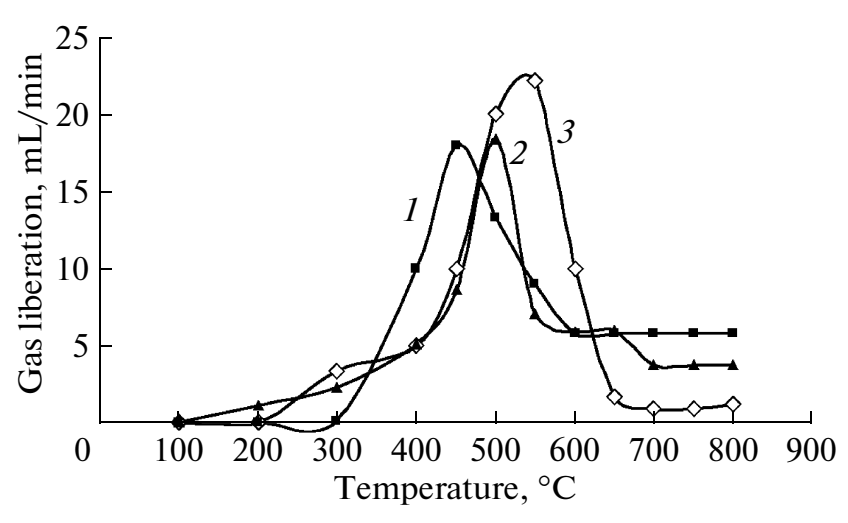

Fig. 2. Carbonization of pitch with $\mathrm{TiO}_{2}$ : (1) HTP $\mathrm{B}+$ $3.8 \% \mathrm{TiO}_{2}$; (2) HTP B $\left(\mathrm{TiO}_{2}\right)$; (3) HTP B.

Our experiments on the carbonization of industrial pitch samples mixed with titanium dioxide (Table 2, experiment 5) and modified with titanium dioxide (Table 2, experiment 6) show that the effect of this additive depends somewhat on the method by which it is introduced in the pitch.

When the $\mathrm{TiO}_{2}$ is mixed with the high-temperature pitch immediately prior to carbonization (method 1 ; Table 2, experiment 5), it has an inhibiting effect, as in [6]. That is confirmed by the reduced yield of pitch coke $\left(72.7 \%\right.$ as against $78.0 \%$ without $\left.\mathrm{TiO}_{2}\right)$ and the increased yield of pitch tar (21.9\%). In the carbonization of pitch modified by titanium dioxide (method 2; Table 2, experiment 6), the yield of coke residue increases to $74.2 \%$.

Adding $\mathrm{TiO}_{2}$ markedly affects the gas-liberation dynamics: the gas-liberation peak is shifted to lower temperatures. That indicates earlier destruction and the formation of coke structures (Fig. 2). The effect is most pronounced in method 1 (Fig. 2, curve 1). In method 2, with modification of the high-temperature pitch, the gas-liberation peak is in an intermediate position (Fig. 2, curve 2).

Note that, with any method of $\mathrm{TiO}_{2}$ introduction, the rate of gas liberation and the volume of the exhaust gases are increased. According to the experimental data, despite the increased of pitch tar in the presence of titanium dioxide, the benz $[a]$ pyrene content in the pitch tar is less than half of the value with no additive, thereby confirming that titanium dioxide reduces the carcinogenic impact of pitch processing. In the carbonization of pitch with titanium dioxide, the benz $[a]$ pyrene content in the exhaust gases at temperatures up to $800^{\circ} \mathrm{C}$ is markedly reduced, especially in the case of mechanical mixing (Table 2, experiments 5 and 6). On that basis, we conclude that adding titanium dioxide in the carbonization of high-temperature pitch reduces the carcinogenic impact and may be recommended as a means of reducing carcinogenic atmospheric emissions.

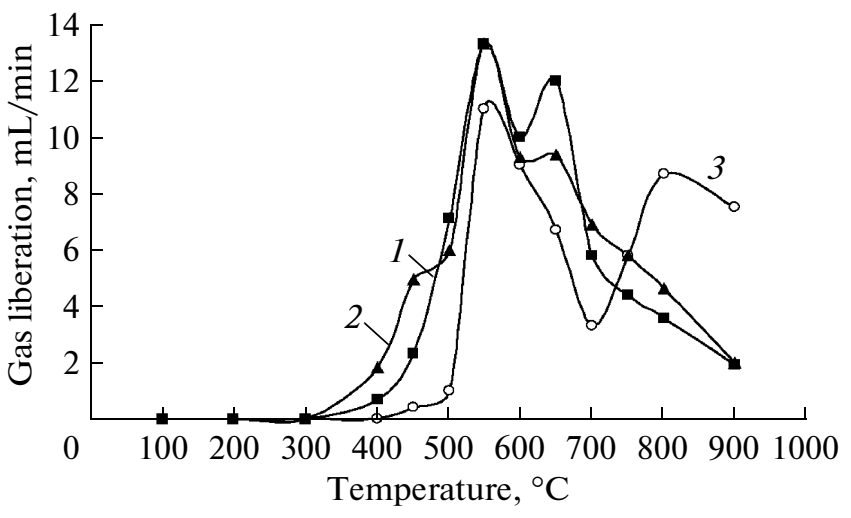

Fig. 3. Carbonization of pitch with finely disperse carbon: (1) HTP A + FDC; (2) HTP A(FDC); (3) HTP A.

The introduction of solid carbon particles in coal pitch increases the reactive surface for condensation processes, thereby increasing the carbonization rate. As a rule, that increases the rate of coke formation and the coke yield. A method for pitch-coke production was proposed in [7]. In that method, the introduction of $10-30 \%$ graphitized electrode dust in the pitch prior to coking increases the yield of pitch coke.

If small quantities (3-5\%) of adsorbents with mean pore size $2.6-3.7 \mathrm{~nm}$ are introduced in anodic pitch binder, the emission of carcinogenic polycyclic aromatic hydrocarbons (benz $[a]$ pyrene and benz $[a]$ anthracene) from self-baking Soderberg anodes may be almost completely eliminated, according to the data in [8]. That is due to selective adsorption of the carcinogenic polycyclic aromatic hydrocarbons by the adsorbent (activated carbon), according to [7]. However, no explanation has been offered for such selective adsorption.

In the experiments, we use finely disperse carbon as the additive, with the following fractional composition: $59.0 \%$ of the $>0.005-\mathrm{mm}$ class; $5.6 \%$ of the $<0.05-\mathrm{mm}$ class; $33.6 \%$ of the $>0.10-\mathrm{mm}$ class; and $1.8 \%$ of the $>0.25-\mathrm{mm}$ class.

Our experiments on the carbonization of industrial HTP and MTP samples with finely disperse carbon confirm the conventional view that the yield of coke residue is increased (Table, experiments 7-9).

Judging from Fig. 3, the finely disperse carbon significantly modifies the gas-liberation dynamics in the carbonization of pitch, with preparation both by mechanical mixing and by modification. In the presence of finely disperse carbon, gas liberation begins earlier and is more rapid. That undoubtedly indicates earlier coke formation.

The difference in the gas-liberation rate is most significant at high temperatures $\left(650-900^{\circ} \mathrm{C}\right)$. In that region, the finely disperse carbon tends to lower the rate of gas liberation (Fig. 3, curves 1 and 2) in comparison with the case where carbon is absent (Fig. 3, curve 3).

COKE AND CHEMISTRY Vol. $56 \quad$ No. 12013 
Table 4. Composition of polycyclic aromatic hydrocarbons in pitch tar

\begin{tabular}{|c|c|c|c|}
\hline \multirow{2}{*}{ Polycyclic aromatic hydrocarbon } & \multirow{2}{*}{$\begin{array}{l}\text { Retention time, } \\
\text { min }\end{array}$} & \multicolumn{2}{|c|}{$\begin{array}{c}\text { Composition (\%) of polycyclic aromatic hydrocarbons } \\
\text { in pitch tar from }\end{array}$} \\
\hline & & HTP A & HTP A + FDC \\
\hline Naphthalene & 8.38 & 0.44 & 0.59 \\
\hline Biphenyl & 11.06 & - & 0.04 \\
\hline Acenaphthylene & 12.06 & - & 0.11 \\
\hline Acenaphthene & 12.51 & 0.12 & 0.47 \\
\hline Fluorene & 13.85 & 0.09 & 0.23 \\
\hline Phenanthrene & 16.74 & 0.84 & 1.96 \\
\hline Anthracene & 16.91 & 0.24 & 0.63 \\
\hline Fluoranthene & 21.18 & 4.62 & 6.21 \\
\hline Pyrene & 22.07 & 4.03 & 5.26 \\
\hline Benz $[a]$ anthracene & 27.38 & 3.88 & 3.87 \\
\hline Chrysene & 27.55 & 7.43 & 5.22 \\
\hline Benz $[b]$ fluoranthene & 32.10 & 4.77 & 2.31 \\
\hline Benz $[k]$ fluoranthene & 32.16 & 2.78 & 1.87 \\
\hline Benz $[e]$ pyrene & 33.27 & 2.63 & 1.32 \\
\hline Benz $[a] p y r e n e$ & 33.49 & 2.46 & 1.72 \\
\hline Inden $[1,2,3-c, d]$ pyrene & 39.83 & 1.21 & 0.81 \\
\hline Dibenz $[a, h]$ anthracene & 40.06 & 0.37 & 0.22 \\
\hline Benz $[g, h, i]$ perylene & 41.55 & 1.03 & 0.58 \\
\hline Sum of polycyclic aromatic hydrocarbons & & 36.94 & 33.41 \\
\hline $\begin{array}{l}\text { Sum of carcinogenic polycyclic aromatic } \\
\text { hydrocarbons }\end{array}$ & & 28.4 & 22.2 \\
\hline
\end{tabular}

Note: Carcirogenic polycyclic aromatic hydrocarbons are in bold.

As would be expected, the change in the gas-liberation dynamics affects the rate of benz $[a]$ pyrene emission. Analysis shows that, in the presence of finely disperse carbon, the total benz $[a]$ pyrene content in the gas is reduced, as well as the content of pitch sublimates (Table 4). By increasing the reactive surface, the finely disperse carbon stimulates the destruction of high-molecular hydrocarbons, as established by comparing the composition of the pitch sublimates in the presence and absence of the carbon (Table 4).

It follows from Table 4 that, in the presence of finely disperse carbon, the yield of pitch tar is reduced, on account of the significant reduction in concentration of high-molecular polycyclic aromatic hydrocarbons, beginning with benz $[a]$ anthracene. For example, the benz $[a]$ pyrene content is reduced by about a $43 \%$, while the benz $[b]$ fluoranthene content is reduced by as much as a half. The concentration of relatively low-molecular polycyclic aromatic hydrocarbons in the pitch tar, conversely, is increased. The total quantity of carcinogenic polycyclic aromatic hydrocarbons in the pitch tar is also reduced in the presence of finely disperse carbon.
On account of the earlier onset of destruction, high-temperature pitch modified by finely disperse carbon (method 2) is characterized by greater gas liberation and the benz $[a]$ pyrene content in the exhaust gases is higher up to $750^{\circ} \mathrm{C}$ (Table 2, experiment 7). However, at $800^{\circ} \mathrm{C}$ and above, the benz $[a]$ pyrene content in the gas is less than in the absence of finely disperse carbon (Table 2, experiment 1). These data are in good agreement with the reduced rate of gas liberation in the high-temperature carbonization of pitch with finely disperse carbon (Fig. 4).

The influence of finely disperse carbon is more apparent in the case of mechanical mixing with medium-temperature pitch (Fig. 4, curves 2 and 3). Adding finely disperse carbon to medium-temperature pitch significantly accelerates low-temperature gas liberation and shifts the gas-liberation peak toward higher temperatures by comparison with the peak for high-temperature pitch (Fig. 4, curve 1). The yield of coke residue in the carbonization of medium-temperature pitch with finely disperse carbon (78\%) is practically the same as in the carbonization of VTP A pitch. 


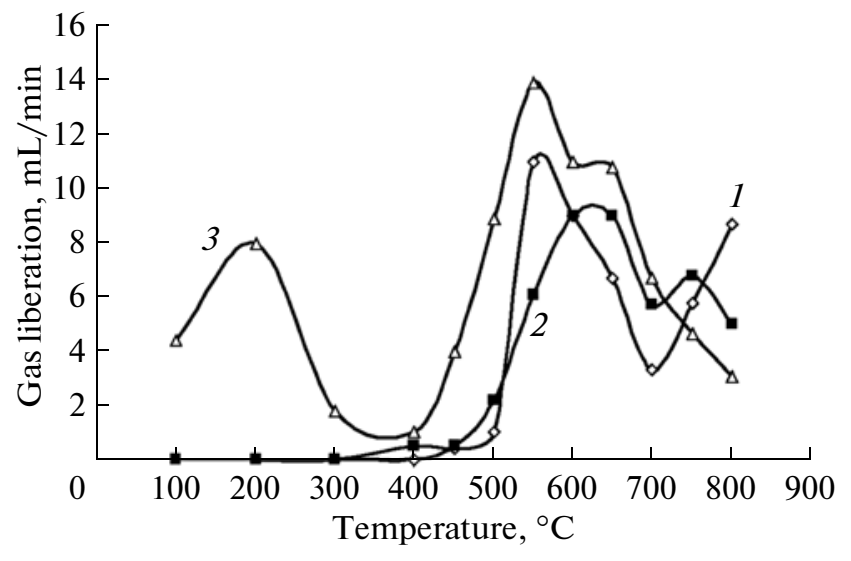

Fig. 4. Carbonization of pitch with finely disperse carbon: (1) HTP; (2) MTP; (3) MTP + FDP.

As for high-temperature pitch, some increase in the benz $[a]$ pyrene content in the exhaust gases is observed in the carbonization of medium-temperature pitch with finely disperse carbon up to $750^{\circ} \mathrm{C}$, with significant decrease in the benz $[a]$ pyrene content at $800^{\circ} \mathrm{C}$ and above (Table 2, experiment 9). In this case, as in some others, the increase in benz $[a]$ pyrene content in the exhaust gases at low temperatures may be attributed to the greater gas liberation. In the carbonization of medium-temperature pitch with finely disperse carbon, the benz $[a]$ pyrene content in the exhaust gases up to $750^{\circ} \mathrm{C}$ is $53.8 \mathrm{ng} / \mathrm{g}$ of pitch, while the gas yield is $358 \mathrm{~mL} / \mathrm{g}$ of pitch; in the presence of finely disperse carbon, the corresponding figures are $27.9 \mathrm{ng} / \mathrm{g}$ and $164 \mathrm{~mL} / \mathrm{g}$.

In the heterogeneous carbonization of pitch, the increased reactive surface in the presence of finely disperse carbon is also observed in the case of faster heating (when the quartz reactor with the charge is lowered into a furnace heated to $800^{\circ} \mathrm{C}$ ). Comparative experiments show that the yield of coke residue and the benz $[a]$ pyrene content in the exhaust gases are very different in the fast carbonization of HTP A pitch with and without finely disperse carbon (Table 2, experiments 12 and 13).

The benz $[a]$ pyrene content in the exhaust gases at $750-800^{\circ} \mathrm{C}$ does not depend on its concentration in the initial pitch, according to [9]. That finding may probably be extended to other hydrocarbons subjected to carbonization, including those from petroleum processing. Our experiments on the carbonization of HTP A coal pitch (containing $0.95 \%$ benz $[a]$ pyrene) with the addition of petroleum bitumen (containing $0.06 \%$ benz $[a]$ pyrene) confirm this conclusion.

Adding bitumen with a low content of carcinogenic components somewhat reduces the benz $[a]$ pyrene content in the pitch tar but significantly increases its content in the exhaust gases (Table 2).

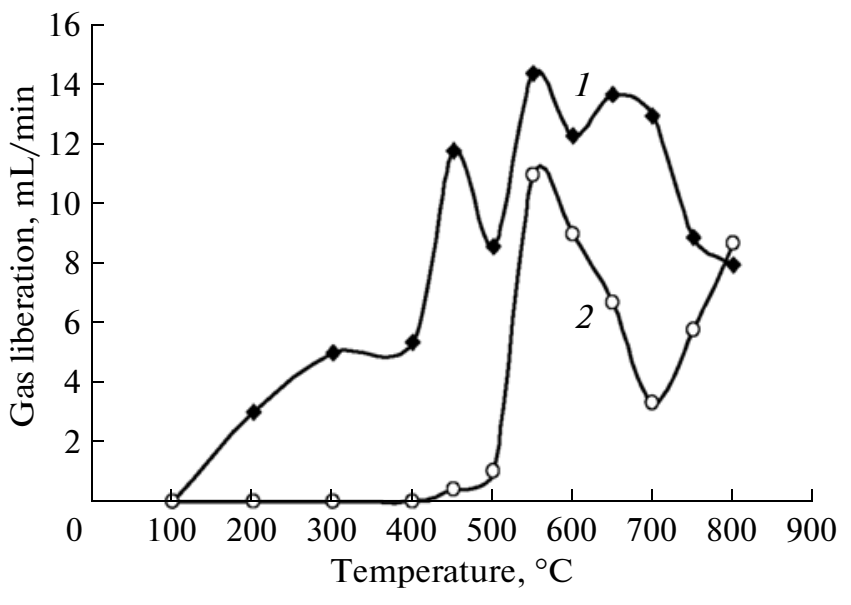

Fig. 5. Carbonization of pitch with petroleum bitumen: (1) HTP A + bitumen; (2) HTP A.

Whereas the benz $[a]$ pyrene content in the exhaust gases at $750-900^{\circ} \mathrm{C}$ in the carbonization of HTP A pitch is $18.6 \mathrm{ng} / \mathrm{g}$, it increases to $31.5 \mathrm{ng} / \mathrm{g}$ on adding petroleum bitumen (Table 2, experiments 1 and 11).

In Fig. 5, we show that the carbonization of pitch with petroleum bitumen increases the rate of gas liberation and the number of extremal points. In addition, despite the increased total benz $[a]$ pyrene content in the exhaust gases, especially at high temperatures, the mean benz $[a]$ pyrene content in the gas is lower, on account of the increased total yield of gas.

The addition of petroleum byproducts with low benz $[a]$ pyrene content to coal binder is often regarded as a means of reducing the carcinogenic impact of electrode production and operation.

Our results indicate that the use of hybrid petroleum-coal binders does not always eliminate the environmental impact of pitch treatment, if the content of carcinogenic polycyclic aromatic hydrocarbons in the exhaust gases is not reduced. The main atmospheric pollutant is the benz $[a]$ pyrene synthesized in the hightemperature carbonization of the pitch, rather than the benz $[a]$ pyrene initially present in the pitch.

The addition of transition metals (including Fe and $\mathrm{Ni})$ reduces (or even eliminates) benz $[a]$ pyrene emissions in the carbonization of pitch, according to [10]. We have been unable to duplicate those results: with the addition of $4.8 \% \mathrm{NiCl}_{2}$, the benz $[a]$ pyrene content in the exhaust gases is no less than with no $\mathrm{NiCl}_{2}$.

The most important conclusions from our experiments are as follows.

(1) By introducing various additives in the carbonization of coal pitch, we may modify the gas-liberation dynamics and the rate and degree of coke formation and consequently the yield and properties of the main carbonization products: coke, tar, and gas. The method by which the additives are introduced matters. 
(2) By means of additives, we may effectively reduce the liberation and rate of liberation of benz $[a]$ pyrene and other carcinogenic polycyclic aromatic hydrocarbons from pitch in carbonization. However, this applies most fully to the hydrocarbons that evaporate and condense as pitch tar.

Some additives undoubtedly affect the benz $[a]$ pyrene content in the exhaust gases. However, the main source of benz $[a]$ pyrene and other polycyclic aromatic hydrocarbons is high-temperature synthesis in the gas phase, where the additives have little influence and the most important factors are associated with the kinetics of pyrolysis, such as the initial concentration of the materials from which polycyclic aromatic hydrocarbons may be synthesized; their residence time in the reaction zone; and the degree of conversion of the polycyclic aromatic hydrocarbons produced.

Note that the carbonization of pitch with polymer additives (for example, with PET), which increases the gas liberation, is accompanied by increase in the benz $[a]$ pyrene content in the exhaust gases, probably as a result of the reduced residence time of the gas in the high-temperature zone.

(3) If petroleum byproducts with reduced content of carcinogenic polycyclic aromatic hydrocarbons are added to coal pitch, the benz $[a]$ pyrene content in the exhaust gases is not affected and consequently the environmental impact of pitch treatment will not necessarily be reduced. The main atmospheric pollutant is the benz $[a]$ pyrene synthesized in the high-temperature carbonization of the pitch, rather than the benz $[a]$ pyrene initially present in the pitch.

In this context, we should correct the prevailing view that petroleum binder is superior to coal binder, on account of the greater benz $[a]$ pyrene content in coal binder.

Our experimental data indicate that the environmental impact of pitch carbonization will be basically the same for pitch derived from coal or petroleum, so long as a closed system for the trapping and condensation of pitch tar (pitch sublimates) is employed. In reality, their atmospheric emissions will be equally harmful unless the content of carcinogenic polycyclic aromatic hydrocarbons is minimized by catalytic treatment.

\section{REFERENCES}

1. Sidorov, O.F., Carbonization of Coal Pitch with Reduced Liberation of Carcinogenic Hydrocarbons, Koks Khim., 2012, no. 2, pp. 33-39.

2. Gol'dshtein, L.M., Fomina, N.V., Gorpinenko, M.S., et al., Kinetics of Binder Carbonization in Pitch-Coke Composites with Added PET, Khim Tverd. Topl., 1984, no. 1, pp. 126-129.

3. US Patent 2004131857.

4. Diez, M.A., Alvarez, R., Barriocanal, C., et al., Effect of the Addition of Different Plastic Wastes to Coal on the Formation of Semicoke, Proceedings of the Carbon Conference, Oviedo, Spain, 2003.

5. Vivero, L., Canga, C.S., et al., Modification of Fluidity of Coking Coals by Plastic Waste Addition, Proceedings of the Carbon Conference, 2005.

6. Kubica, K., Topolnicka, T., and Kordas, T., The Influence of Titanium Oxide on PAHs Behavior during the Process of Coal Pitch Thermolysis, Proceedings of the Carbon Conference, 2005.

7. Malyutina, E.M., Dyskina, B.Sh., and Korchazhkina, O.F., Russian Patent 3278320, 2008.

8. Anshits, A.G., Nizov, V.A., Suzdorf, A.R., and Savinov, V.I., Russian Patent 2088694, 1997.

9. Sidorov, O.F., Liberation Dynamics of Carcinogenic Hydrocarbons in the Carbonization of Coal Pitch and Composites, Koks Khim., 2012, no. 12, pp. 28-34.

10. Barnakov, Ch.N., Sent-Ablaeva, S.K., Kozlov, A.P., et al., Russian Patent 2370837, Byull. Izobret., 2009, no. 29 . 